\title{
Environmental regulation of the purine synthesis enzyme purH transcript during adult diapause in Leptinotarsa decemlineata (Coleoptera: Chrysomelidae)
}

\author{
GeORGE D. YOCUM
}

Red River Valley Agricultural Research Center, USDA, ARS, Biosciences Research Laboratory, 1605 Albrecht Boulevard, Fargo, ND 58105-5674; e-mail: yocumg@fargo.ars.usda.gov

Key words. Diapause, Colorado potato beetle, gene expression, purine

\begin{abstract}
A 1962 bp cDNA clone of 5-aminoimidazole-4-carboxamide ribonucleotide formyltransferase/IMP cyclohydrolase ( $p u r H$ ) was isolated from diapausing adults of Leptinotarsa decemlineata using RT-PCR and 3' and 5'-RACE. The probe generated from this clone hybridized to a transcript approximately $1960 \mathrm{bp}$ in length on northern blots. The clone encodes for a deduced protein 594 amino acids in length with $73 \%$ identity, $83 \%$ similarity to purH from Drosophila melanogaster. Northern blot (total RNA) analysis determined that $L$. decemlineata purH $(\mathrm{LdpurH})$ was downregulated in diapausing beetles stored at $10^{\circ} \mathrm{C}$. Developmental studies revealed that $L d p u r H$ is expressed at nearly constant high levels in both nondiapausing and prediapause adults. $L d p u r H$ expression during the first 20 days of diapause is equivalent to that seen in nondiapausing beetles, after which expression decreases. Exposing 70 day old diapausing beetles to $20^{\circ} \mathrm{C}$ for $24 \mathrm{~h}$ induced an increase in expression of purH indicating that purH is regulated by temperature in diapausing/overwintering beetles.
\end{abstract}

\section{INTRODUCTION}

Environmental conditions required for reproduction and development are normally restricted to only a small part of the year, especially in the temperate zones where organisms must survive winter with its associated low temperatures, low humidity and lack of food. Even in tropical regions, organisms may not have optimal yearround growing conditions due to seasons characterized by heavy rains or high temperatures. To survive these recurring and predictable periods of environmental stress, a wide spectrum of organisms employs some form of dormancy. The ability to enter into a state of dormancy is normally restricted to one developmental stage of an organism's life cycle and is characterized by suppressed metabolism and increased tolerance of environmental stresses.

Independent of phyla, dormancy in most organisms shares many physiological characteristics such as decreased respiration and protein synthesis, cell cycle arrest, stockpiling of metabolic reserves, and unique gene expression patterns. Another feature common to dormancy is the role of nucleotides in dormancy bioenergetics and regulation. Cyclic GMP but not cAMP terminates diapause when injected into diapausing flesh fly, Sarcophaga crassipalpis (Denlinger \& Wingard, 1978). Cyclic AMP levels are 6-fold higher in nondiapause-programmed $S$. crassipalpis pupal brains and ring glands than in diapausing pupae. Injection of cholera toxin induces an increase in cAMP in diapauseprogrammed pupae and averts diapause (Gnagey \& Denlinger, 1983). Co-injecting cGMP with 20-hydroxyecdysone $(20 \mathrm{HE})$ increases the efficacy of $20 \mathrm{HE}$ termination of pupal diapause in the Bertha armyworm, Mamestra configurata, whereas cAMP blocks $20 \mathrm{HE}$ termination of diapause (Bodnaryk, 1975). In the freshwater sponge Spongilla lacustris cAMP titer drops at the initiation of dormancy termination. Blocking cAMP metabolism with a cAMP-phosphodiesterase inhibitor arrests the termination of dormancy (Simpson \& Rodan, 1976). Injecting AMP into pharate adult female Bombyx mori programmed to produce diapausing eggs induces the production of nondiapausing eggs, though ATP fails to induce a change in the diapause programming (Suzuki et al., 1978). Brains from B. mori pupae programmed to lay diapausing eggs as adults contain significantly more diand tri-phosphate than brains from pupae of nondiapause egg-producing females. Females programmed to produce non-diapause eggs can be induced to produce diapausing eggs by injecting the medium from cultures containing a mixture of nucleotides and the brain-subesophageal ganglion complexes from pupae programmed to be nondiapause egg-producing females. This indicates a role for free nucleotides in the regulation of $\mathrm{DH}$ (Wu et al., 1996). In the emma field cricket, Teleogryllus emma, and $B$. mori CTP titers drop at the initiation of embryonic diapause (Izumiyama \& Suzuki, 1986: Suzuki \& Miya, 1983). Inducing a developmental arrest by placing nondiapausing $B$. mori eggs under nitrogen also leads to a decrease in CTP titer to levels equivalent to those in diapausing eggs (Suzuki \& Miya, 1983). It is clear from the literature that at the biochemical level various nucleotides are key components in the regulatory mechanism(s) of dormancy.

Our understanding of the molecular basis of all insect diapause is still very fragmented with many key metabolic and regulatory pathways not yet explored. The goal of this investigation is to clarify the possible molecular mechanism for purine regulation during adult diapause in the Colorado potato beetle, the major defoliator of potato (Hare, 1990). This report describes the isolation and char- 
acterization of a full-length cDNA clone that encodes for the enzyme 5-aminoimidazole-4-carboxamide ribonucleotide formyltransferase/IMP cyclohydrolase (purH) that catalyzes the last two steps in de novo synthesis of purines. $\mathrm{PurH}$ is constitutively expressed at high levels in nondiapausing and prediapause adults of Leptinotarsa decemlineata. The level of expression of purH decreases in diapausing beetles after 20 days at $10^{\circ} \mathrm{C}$. Increasing temperature from $10^{\circ} \mathrm{C}$ to $20^{\circ} \mathrm{C}$ induces an increase in expression of $\mathrm{purH}$ in diapausing beetles, indicating that purH is environmentally regulated in diapausing/overwintering beetles.

\section{MATERIAL AND METHODS}

\section{Insect rearing}

L. decemlineata were reared according to Yocum (2001). To obtain nondiapausing adults the colony was maintained at $17 \mathrm{~L}: 7 \mathrm{D}, 26 \pm 2^{\circ} \mathrm{C}$ and $65 \%$ relative humidity. Diapausing adults were obtained by rearing larvae, pupae and adults at $8 \mathrm{~L}: 16 \mathrm{D}$, $24 \pm 2{ }^{\circ} \mathrm{C}$ and $65 \%$ relative humidity. Diapause-programmed adults were given potato leaves for 20 days, then placed in moist vermiculite and stored at $10^{\circ} \mathrm{C}$ in constant darkness.

\section{RNA isolation}

Total RNA was isolated from adults by mincing a single beetle in a $2 \mathrm{ml}$ RNase-free microcentrifuge tube with $0.5 \mathrm{ml}$ TRIzol $^{\circledR}$ reagent (Invitrogen, Carlsbad, USA), then adding another $0.5 \mathrm{ml} \mathrm{TRIzol}{ }^{\circledR}$. Samples were centrifuged at $12,000 \mathrm{~g}$ for $10 \mathrm{~min}$ and the supernatant was transferred to a new $2 \mathrm{ml}$ RNase-free microcentrifuge tube with another $0.5 \mathrm{ml} \mathrm{TRIzol}{ }^{\circledR}$. Samples were then stored at $-70^{\circ} \mathrm{C}$ until the RNA was purified following the manufacturer's protocol. The isolated RNA pellets were stored under absolute ethyl alcohol at $-70^{\circ} \mathrm{C}$ and later dis- solved in either $30 \mu \mathrm{l}$ formamide for northern blot analysis or 30 $\mu 1$ sterile water for construction of the $3^{\prime}$ and 5'-RACE cDNA templates.

\section{3' and 5'-RACE}

The original partial cDNA clone of purH was isolated using RT-PCR, and a gene-specific primer was designed for use in the 5'-RACE reaction. Single strand cDNAs with adapter primer sites at either the $3^{\prime}$ or $5^{\prime}$ end of the cDNA were synthesized according to the manufacturer's protocol starting with $1 \mu \mathrm{g}$ of total RNA (SMART ${ }^{\mathrm{TM}}$ RACE cDNA Amplification Kit, Clontech, Palo Alto, USA). 5'-RACE was carried out according to the manufacturer's instructions. The resulting 5'-RACE clones were isolated and sequenced to determine gene-specific primers for 3'-RACE, and 3'-RACE was carried out according to the manufacturer's instructions. The 3'-RACE clone was used for all sequence data presented here.

\section{Probe labeling}

The digoxigenin labeled probe was synthesized by PCR (PCR Dig Probe Synthesis Kit, Roche, Indianapolis, USA) according to the manufacturer's protocol at a $1: 3$ ratio of digoxigenindUTP to dTTP and using approximately $40 \mathrm{pg}$ of the 3 '-RACE clone as the template.

\section{Northern blot analysis}

Five micrograms of total RNA per sample were separated on a $1 \%$ agarose denaturing gel $(0.41 \mathrm{M}$ formaldehyde, $1 \mathrm{X}$ MOPSEDTA-sodium acetate). To ensure that equivalent RNA was loaded for each sample, ethidium bromide was added to all samples and a photograph was taken at the end of the gel run to compare rRNA band intensity. The RNA was then transferred overnight onto a positively charged nylon membrane (Roche) using downward capillary action in 20X SSC (3 M NaCl, $0.3 \mathrm{M}$ $\mathrm{Na}$ citrate, $\mathrm{pH}$ 7.0) transfer buffer (Schleicher and Schuell,

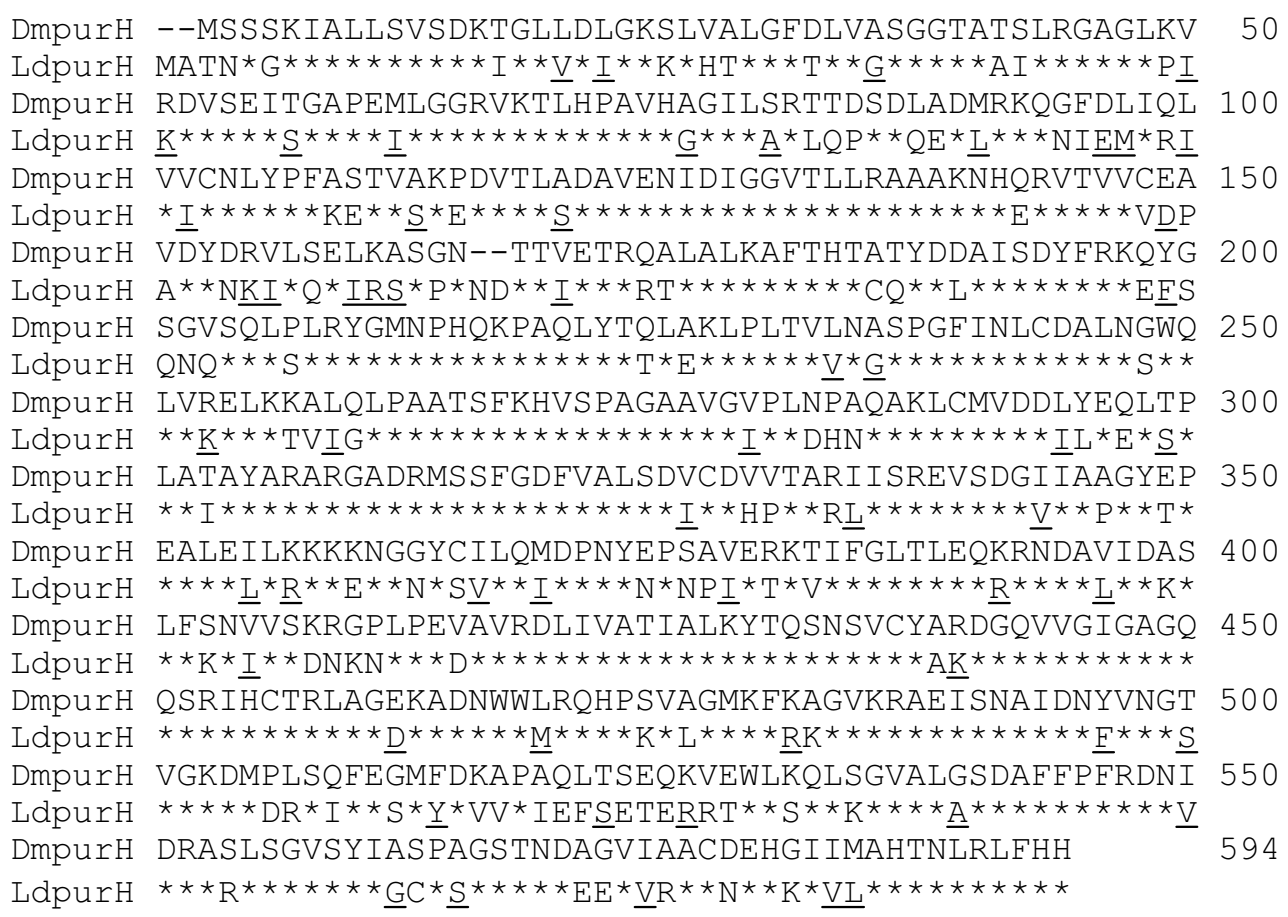

Fig. 1. Amino acid alignment of Drosophila melanogaster purH (accession number CG11089) and the LdpurH deduced protein. Analysis (AlignX, InforMax) of the two proteins yielded a score of $73 \%$ identity, $83 \%$ similarity. Amino acid number is given to the right of each row. Similar/chemically equivalent amino acids are underlined. (*) identical amino acids, $(-)$ insertion or deletion. 
Keene, USA). After completion of the transfer the blots were air-dried and then UV crosslinked at $12,000 \mu \mathrm{J} / \mathrm{cm}^{2}$ and the filters stored at $-20^{\circ} \mathrm{C}$. Prehybridization and hybridization were carried out in Dig Easy Hybridization Buffer ${ }^{\mathrm{TM}}$ (Roche). The final probe concentration was $20 \mathrm{ng} / \mathrm{ml}$ of hybridization buffer. The digoxigenin labeled probes were detected using Dig High Prime DNA Labeling and Detection Start Kit II (Roche). Each northern blot represents duplicate samples.

\section{DNA sequencing}

The clone was sequenced using the vector internal primer sites and custom primers internal to the inserts. DNA sequencing was performed at the University of Georgia on an ABI 373 DNA sequencer (Foster City, USA) using dye terminator chemistry according to the manufacturer's standard protocol. The BlastX program (Altschul et al., 1997) was used to search the GenBank sequence repository for sequence identity.

\section{GenBank}

The nucleotide sequences for $L d p u r H$ was deposited in GenBank and assigned the accession number AY357301.

\section{RESULTS}

\section{cDNA clone and deduced protein}

Following 5' and 3'-RACE a 1962 bp cDNA clone was isolated. Probes generated from this clone screened against a northern blot hybridized a transcript approximately $1960 \mathrm{bp}$ in length. The clone contained a $1782 \mathrm{bp}$ open reading frame encoding for a deduced protein of 594 amino acids in length. The tentative open reading frame is bracketed by multiple stop codons on each side. BlastX search revealed that the closest match to the deduced protein was purH from Drosophila melanogaster (accession number CG11089). Alignment of the two proteins yielded a score of $73 \%$ identity, $83 \%$ similarity (AlignX, InforMax) (Fig. 1).

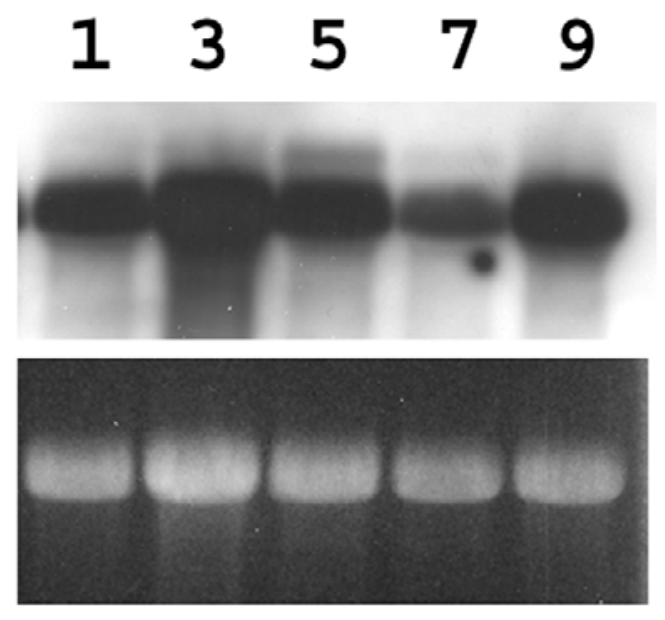

Fig. 2. Northern blot analysis of $L d p u r H$ expression in nondiapausing adults of $L$. decemlineata. Total RNA ( $5 \mu \mathrm{g})$ isolated from adults 1, 3, 5, 7 and 9 days post eclosion was separated on a $1 \%$ formaldehyde-agarose gel and transferred onto a positively charged nylon membrane. The northern blots were hybridized using digoxigenin PCR labeled probe. RNA concentrations were determined spectrophotometrically and stained with ethidium bromide to ensure equal loading. Ethidium bromide stained ribosomal RNA is shown below its respective northern blot.

\section{Developmental expression of purH expression}

A series of developmental profiles were generated to determine if $L d p u r H$ is developmentally regulated. In nondiapausing adults for at least 9 days post emergence, a period that includes mating and the first round of oviposition, $L d p u r H$ is expressed at constant high levels (Fig. 2). Comparison of $L d p u r H$ expression between nondiapausing adults and beetles in diapause for 60 to 90 days reveals that $L d p u r H$ is downregulated during diapause (Fig. 3A). To investigate when LdpurH synthesis is decreased in response to the diapause program, its expression was examined in prediapause adults and at the initiation of diapause. Diapause-programmed adults will emerge from the soil and actively feed; by day 10 to 15 there is a marked decrease in feeding and by day 20 all the beetles will be in diapause. The expression level of $L d p u r H$ throughout the prediapause period and at the onset of diapause (days 18 to 21 ) is equivalent to that seen in the nondiapause control (Fig. 3B). To determine when LdpurH is downregulated during diapause, RNA samples were collected from beetles 1, 20, 40, 60 and 80 days in diapause. $L d p u r H$ expression begins decreasing approximately 20 days into diapause and remains below

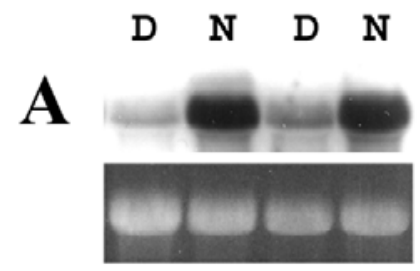
$\begin{array}{lllllllll}\mathrm{N} & 1 & 3 & 6 & 9 & 12 & 15 & 18 & 21\end{array}$

B
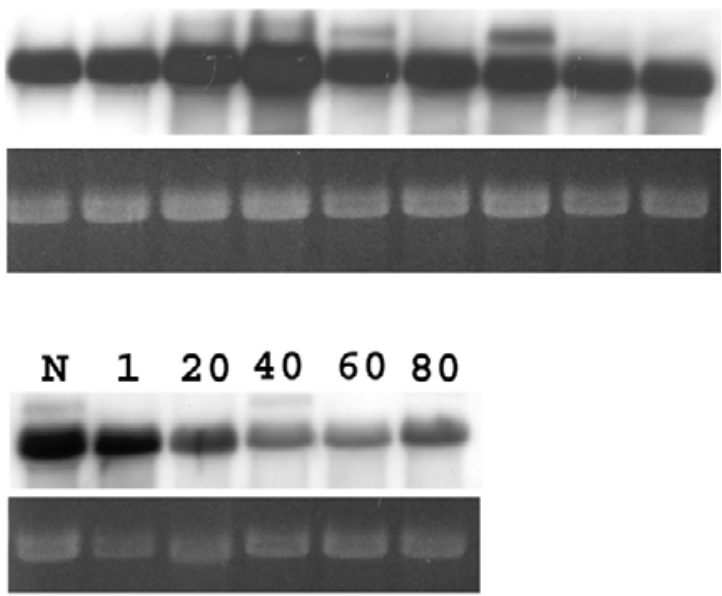

Fig. 3. Northern blot analysis of $L d p u r H$ expression during diapause development in $L$. decemlineata: (A) Nondiapausing (N) and diapausing (D) adults; (B) Analysis of $L d p u r H$ expression in diapause-programmed adults 1-21 days post eclosion; (C) $L d p u r H$ expression in 1, 20, 40, 60 and 80 day diapausing adults. Total RNA $(5 \mu \mathrm{g})$ was separated on a $1 \%$ formaldehydeagarose gel and transferred onto a positively charged nylon membrane. The northern blots were hybridized using digoxigenin PCR labeled probe. RNA concentrations were determined spectrophotometrically and stained with ethidium bromide to ensure equal loading. Ethidium bromide stained ribosomal RNA is shown below its respective northern blot. 


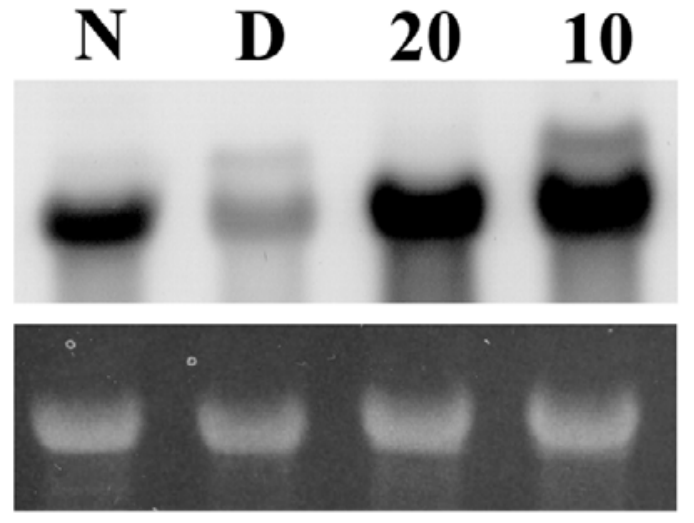

Fig. 4. Northern blot analysis of environmental regulation of LdpurH expression. Nondiapausing (N) and diapausing (D) adults, diapausing adults transferred from $10^{\circ} \mathrm{C}$ to $20^{\circ} \mathrm{C}$ for $24 \mathrm{~h}$ (20), diapausing adults transferred from $10^{\circ} \mathrm{C}$ to $20^{\circ} \mathrm{C}$ for $24 \mathrm{~h}$ followed by a $24 \mathrm{~h}$ exposure to $10^{\circ} \mathrm{C}(10)$. Total RNA $(5 \mu \mathrm{g})$ was separated on a $1 \%$ formaldehyde-agarose gel and transferred onto a positively charged nylon membrane. The northern blots were hybridized using digoxigenin PCR labeled probe. RNA concentrations were determined spectrophotometrically and stained with ethidium bromide to ensure equal loading. Ethidium bromide stained ribosomal RNA is shown below its respective northern blot.

the levels seen in nondiapause beetles for at least 80 days into diapause (Fig. 3C).

\section{Environmental regulation of purH}

To investigate the possibility of environmental regulation of purH in diapausing/overwintering Colorado potato beetles, the beetles were exposed to two different temperature regimes. Beetles in diapause for 70 days at $10^{\circ} \mathrm{C}$ were exposed to $20^{\circ} \mathrm{C}$ for $24 \mathrm{~h}$ and then either harvested immediately or exposed to $10^{\circ} \mathrm{C}$ for $24 \mathrm{~h}$ before harvest. PurH was highly upregulated in both experimental groups as compared to the diapause and nondiapause positive controls (Fig. 4).

\section{CONCLUSIONS AND DISCUSSION}

PurH is a multi-function protein best known for its role in purine synthesis. PurH catalyzes the last two steps in the de novo synthesis of purines, resulting in the synthesis of inosine monophosphate (IMP), which is rapidly converted into adenosine monophosphate (AMP) and guanosine monophosphate (GMP). PurH is a bifunctional enzyme in all prokaryotic and eukaryotic organisms investigated to date, with two independent catalytic sites. The 5-aminoimidazole-4-carboxamide ribonucleotide formyltransferase site is located within 406 amino acids from the $\mathrm{COOH}$-terminus, while the inosine monophosphate cyclohydrolase site is within 223 amino acids from the NH2-terminus (Rayl et al., 1996). PurH is highly conserved at the amino acid level with human purH sharing $31-37 \%$ identity with three bacteria and $81 \%$ identity with chicken purH (Rayl et al., 1996). The predicted amino acid sequence of $L$. decemlineata purH reveals significant identity with that of Drosophila and human purH. LdpurH shares 73\% identity with Drosophila (Fig. 1) and $65 \%$ identity with human (data not shown). In addition to its well-established role as an enzyme, purH also functions in mRNA splicing. In chicken, purH forms a complex with an unidentified $40 \mathrm{kDa}$ protein and then the purH component binds directly to the muscle-specific splicing enhancers of avian troponin T pre-mRNA, controlling the inclusion of the muscle-specific exon 5 (Ryan et al., 2000).

Little is known about the expression of purH during development or stress, although purH appears to be developmentally regulated. In tobacco, Nicotiana tabacum, purH transcript is expressed constitutively at high levels in all tissues examined except for the anthers. In the anthers purH expression increases through development then decreases rapidly after pollination (Boldt et al., 2001). In rats with partial hepatectomy purH expression increases about 7-fold above normal within $24 \mathrm{~h}$ after the operation and then slowly decreases to preoperative levels within 72 h (Akira et al., 1997). Pathogenesis of several microorganisms is associated with upregulation of $\mathrm{purH}$ (Boyce et al., 2002; Lammers et al., 2000). Growing Bacillus anthracis in a nutrient-poor medium that promotes sporulation induces five distinct waves of gene expression. As the medium is depleted and the cells move from exponential growth to stationary growth, $p u r H$ is induced (Liu et al., 2004). As they enter into dormancy, microorganisms investigated to date decrease the expression of purH and other purine synthesis enzymes. Placing Mycobacterium smegmatis under anaerobic conditions alters the expression of 30 genes (including the downregulation of $p u r H$ ), thereby inducing an adaptive stationary-phase response (Murugasu-Oei et al., 1999). As Bacillus subtilis enters early to mid-sporulation, purD, $E, H$, and $M$ are downregulated (Fawcett et al., 2000).

Diapause is a dynamic physiological stage with gene expression patterns changing over the course of diapause development (Denlinger, 2002) and in response to environmental conditions (Denlinger et al., 2001; Yocum, 2001). This multifaceted interaction complicates identifying the mode of regulation of any gene expressed in overwintering insects. A gene may be both diapause and environmentally regulated. In the Colorado potato beetle $H S P 70 A$ is expressed at low levels during diapause, but its expression increases dramatically upon exposure to low temperatures (Yocum, 2001). Or a gene's expression may be altered only under certain environmental conditions, such as after prolonged exposure to low temperature as with $p u r H$. The results presented here underscore how vital it is to recognize the complexity of the interaction between the environment and diapause when investigating gene expression in overwintering insects.

ACKNOWLEDGEMENTS. I thank P.L. Evenson and T.M. Becker, USDA-ARS, Fargo, ND for their technical assistance. I also thank the two anonymous reviewers for their constructive comments and suggestions.

\section{REFERENCES}

Akira T., Komatsu M., Nango R., Tomooka A., Konaka K., Yamauchi M., Kitamura Y., Nomura S. \& TsuKamoto I. 1997: Molecular cloning and expression of a rat cDNA 
encoding 5-aminoimidazole-4-carboxamide ribonucleotide formyltransferase/IMP cyclohydrolase. Gene 197: 289-293.

Altschul S.F., Madden T.L., Schäffer A.A., Zhang J., Zhang Z., Miller W. \& Lipman D.J. 1997: Gapped Blast and PSIBlast: a new generation of protein database search programs. Nucleic Acids Res. 25: 3389-3402.

BODNARYK R.P. 1975: Interaction of cyclic nucleotides and ecdysterone in breaking the pupal diapause of the Bertha armyworm, Mamestra configurata. Life Sci. 16: 1411-1416.

Boldt R., Kunze G., Lerchl J., Lein W. \& Sonnewald U. 2001: Cloning and molecular characterization of the Nicotiana tabacum purH cDNA encoding 5-aminoimidazole-4carboxamideribonucleotide formyltransferase/inosine monophosphate cyclohydrolase. J. Plant Physiol. 158: 1591-1599.

Boyce J.D., Wilkie I., Harper M., Paustian M.L., Kapur V. \& AdLer B. 2002: Genomic scale analysis of Pasteurella multocida gene expression during growth within the natural chicken host. Inflec. Immun. 70: 6871-6879.

Denlinger D.L. 2002: Regulation of diapause. Annu. Rev. Entomol. 47: 93-122.

Denlinger D.L. \& Wingard P. 1978: Cyclic GMP breaks pupal diapause in the flesh fly, Sarcophaga crassipalpis. J. Insect Physiol. 24: 715-719.

Denlinger D.L., Rinehart J.P. \& Yocum G.D. 2001: Stress proteins: a role in insect diapause? In Denlinger D.L., Giebultowicz J.M. \& Saunders D.S. (eds): Insect Timing: Circadian Rhythmicity to Seasonality. Elsevier, Amsterdam, pp. 155-171.

Fawcett P., Eichenberger P., Losick R. \& Youngman P. 2000: The transcriptional profile of early to middle sporulation in Bacillus subtilis. Proc. Natl. Acad. Sci. USA 97: 8063-8068.

Gnagey A.L. \& Denlinger D.L. 1983: Brain and ring gland cyclic AMP and cyclic GMP levels during initiation and termination of pupal diapause in the flesh fly. Comp. Biochem. Physiol. (C) 76: 121-125.

Hare J.D. 1990: Ecology and management of the Colorado potato beetle. Annu. Rev. Entomol. 35: 81-100.

IzUMIYAMA S. \& SUZUKI K. 1986: Nucleotide pools in the eggs of emma field cricket, Teleogryllus emma, and two-spotted cricket Gryllus bimaculatus (Orthoptera: Gryllidae). Appl. Entomol. Zool. 21: 405-410.

Liu H., Bergman N.H., Thomason B., Shallom S., Hazen A., Crossno J., Rasko D.A., Ravel J., Read, T.D., Peterson S.N., Yates J. \& Hanna P.C. 2004: Formation and composition of the Bacillus anthracis endospore. J. Bacteriol. 186: 164-178.

Lammers A., Kruijt E., van de Kuitu C., Nuijten P.J.M. \& SмIтн H. 2000: Identification of Staphylococcus aureus genes expressed during growth in milk: a useful model for selection of genes important in bovine mastitis. Microbiology-UK 146: 981-987.

Murugasu-Oei B., Tay A. \& Dick T. 1999: Upregulation of stress response genes and $\mathrm{ABC}$ transporters in anaerobic stationary-phase Mycobacterium smegmatis. Mol. Gen. Genom. 262: 677-682.

Rayl E.A., Moroson B.A. \& Beardsley G.P. 1996: The human purH gene product, 5-aminoimidazole-4-carboxamide ribonucleotide formytransferase/IMP cyclohydrolase. J. Biol. Chem. 271: 2225-2233.

Ryan K.J., Charlet-B.N. \& CoOper T.A. 2000: Binding of purH to a muscle-specific splicing enhancer functionally correlates with exon inclusion in vivo. J. Biol. Chem. 275: 20618-20626.

Simpson T.L. \& Rodan C.A. 1976: Role of cAMP in the release from dormancy of the freshwater sponge gemmules. Devel. Biol. 49: 544-547.

SuzuKi K., Tsuda S. \& MiYa K. 1978: Occurrence of nondiapause eggs by injection of adenosine-5'-monophosphate into Bombyx mori pupae. Appl. Entomol. Zool. 13: 48-50.

SUZUKI K. \& MiYA K. 1983: Nucleotide pools related to embryogenesis and diapause in eggs of the silkworm, Bombyx mori. J. Sericul. Sci. Japan 52: 12-21.

Wu C., Yamashita T., Taira H. \& SuzuKi K. 1996: Free nucleotide related to the induction of diapause in the silkworm, Bombyx mori. J. Insect Physiol. 42: 441-447.

Yocum G.D. 2001: Differential expression of two HSP70 transcripts in response to cold shock, thermoperiod, and adult diapause in the Colorado potato beetle. J. Insect Physiol. 47: 1139-1145.

Received January 28, 2004; revised April 7, 2004; accepted April 29, 2004 